\title{
ESTUDO QUANTITATIVO E QUALITATIVO DOS PLEXOS DE AUERBACH E MEISSNER DO ESÔFAGO DE CÃES INOCULADOS COM O TRYPANOSOMA CRUZI
}

\author{
Estela R.O. Caliari, Marcelo V. Caliari, Marta de Lana e \\ Washington L. Tafuri
}

\begin{abstract}
Foi realizado um estudo quantitativo e qualitativo dos plexos de Aluerbach e Meissner do esôfago de quatro càes chagásicos sacrificados na fase aguda da infecçâ. As ganglionites e periganglionites do plexo de Auerbach lariaram de discretas a moderadas, induzindo lesoes neuronais significativas, principalmente em dors animais Os gânglios do plexo de Meissner foram observados em pequeno mimero, impossibilitando qualquer análise. Miosite discreta on moderada foi observada principalmente no terço inferior do esófago, raramente associada a nimbos de amastigotas. A contagem de ganglios e neurônios nào demonstrou desnervaçâo. Apesar. de em nenbum dos câes ter sido induzida a formacăo de megaesôfago, relatamos lesöes do plexo de Auerbach e de miocélulas do esófago de animais ma fase aguda da infecçào chagásica. Este parece ser o primeiro estudo quantitativo e qualitatio sistemático dos plexos de Auerbach e Meissner do esôfago na tripanosomiase cruzi experimental.
\end{abstract}

Palatras-chaves: Esôfago. Plexos de Auerbacb e Meissner. Trypanosoma cruzi. Fase Aguda. Cão

Andrade caracterizou bem a fase aguda e a forma indeterminada da cardiopatia chagásica no cão'. Lana inoculando a cepa Be78 em cães caracterizou muito bem a cardiopatia chagásica crônica fibrosante, com quadro clínico e eletrocardiográfico muito semelhante a forma cardiaca humana. Pelo que sabemos, até o momento, nào se documentou claramente a forma digestiva (megaesôfago e megacólon) experimental. Também nao se tem notícias de estudos sistematizados dos neurônios dos plexos de Auerbach e Meissner do esofago na tripanosomíase cruzi experimental. Por estas razòes realizamos o presente trabalho, no pressuposto de encontrar prováveis lesoes neuronais do esôfago na infecçào chagásica experimental canina

Departamentos de Ciências Biológicas do Instituto de Ciências Exatas e Biologicas e de Análises Clínicas da Escola de Farmacia, Universictade Federal de Ouro Preto

Departamento de Patologia Geral do Instituto de Ciencias Biológicas, Universidade Federal de Minas Gerais

Financiado pelo CNPq e FAPEMIG

Enderefo para correspondencia Prof. Marcelo V. Caliari Depto. Patologia Geral/ICB/UFMG. Av. Antōnio Carlos 6627, Pampulha, $31270-010$ Belo Horizonte, MG.

Fax (031) 441-1412

Recebicio para publicação em 04/05/95

\section{MATERIAL E MÉTODOS}

Foram utilizados oito càes de 60 dias de idade, sendo 4 inoculados com 2000 tripomastigotas sanguíneos $/ \mathrm{kg}$ de peso da cepa Be-78 pela via intraperitoneal e 4 controles. Os animais foram mantidos em canil apropriado com dieta ad libitum e observaçào diária. A parasitemia foi avaliada de acordo com Brener ${ }^{2}$.

Os animais foram sacrificados cerca de 30 dias após o inóculo sendo colhido o esôfago in totum de cada um deles. Foram cortados 3 anéis de $6 \mathrm{~mm}$ de espessura: um anel foi cortado $\log o$ abaixo da cartilagem cricoide, correspondente ao terço superior (TS); outro foi cortado logo acima do cárdia, correspondente ao terço inferior (TI) e o último anel foi obtido na regiảo mediana do esôfago, correspondente ao terço médio (TM). Os anéis foram incluídos em parafina, cortados semi-seriadamente $(1: 5) \mathrm{com} 5 \mu \mathrm{m}$ de espessura até o esgotamento total do blocoe, corados pela HE e tricrômico de Gomori. Foram contados todos os gânglios e corpos de neurônios dos plexos de Meissner e Auerbach dos 250 cortes obtidos em média de cada anel. O numero de corpos de neurônio/gânglio dos càes infectados foi comparado em relaçào aos controles através do teste "t" de Student. As ganglionites e periganglionites foram classificadas em discretas (+), moderadas (++) 
Caliari ERO, Caliari MV, Lana M, Tafuri WL. Estudo quantitativo e qualitativo dos plexos de Auerhach $e$ Meissner do esôfago de cães inoculados com o Trypanosoma cruzi. Revista da Sociedade Brasileira de Medicina Tropical 29:17-20, jan-fer: 1996.

e intensas $(+++)$ de acordo com a intensidade do infiltrado inflamatório.

Também foram colhidos fragmentos do miocárdio para detecção da miocardite chagásica e do parasitismo pelo $T$. cruzi.

\section{RESULTADOS}

Todos os animais infectados apresentaram miocardite aguda intensa como já demonstrada em trabalho anterior ${ }^{-1}$. Foram observadas variaçoes anatômicas do esôfago dos animais estudados, inclusive nos càes controles. Uma análise macroscópica mais precisa necessitaria de uma maior amostragem

Ganglionites e periganglionites do plexo de Auerbach foram observadas nas seguintes percentagens: $18.3 \%, 29.2 \%$ e $26 \%$. respectivamente nos terços superior, médio c inferior dos cães infectados (Figura la e Tabela 1). Encarquilhamento, tumefação, picnose, cariólise e tigrólise dos neurônios foram

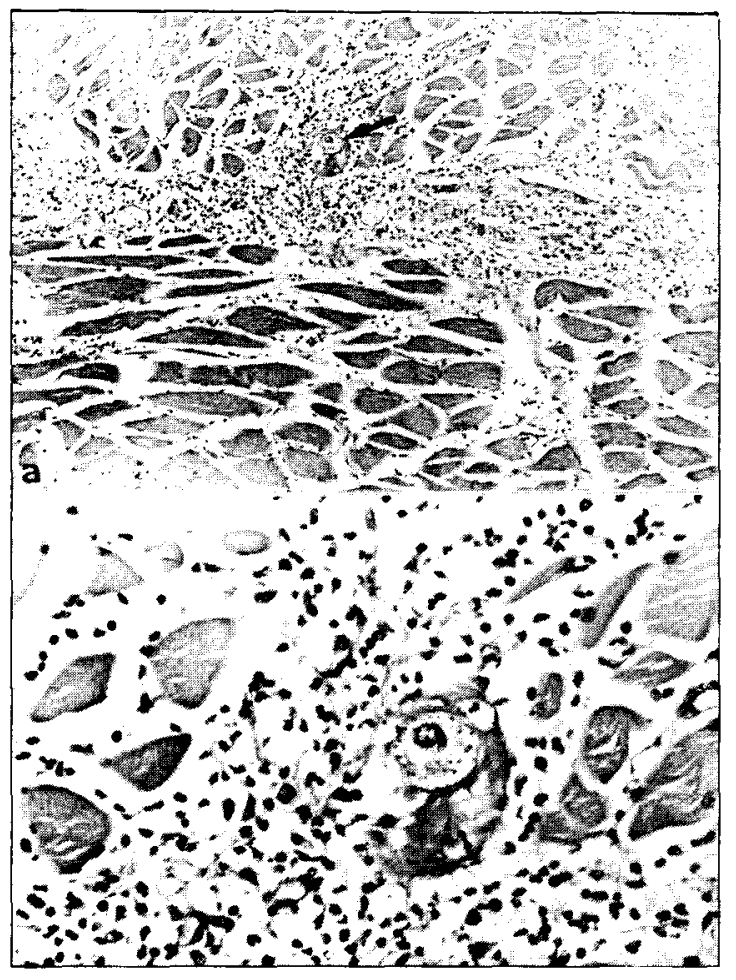

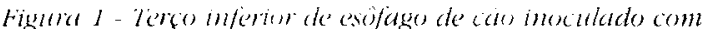
a cepa Be-78 e sacrificado na fase aguda da infeccio: a) miosite, ganglionite e periganglionite do plexo de Auerbach com exsudato predominantemente de células mononucleadas. Miocito vacuolizado contendo formas amastigotas (seta); b) detalbe da figura anterior. $\mathrm{HE}(\mathrm{a})$ $X 200$; (b) $\times 360$. esporadicamente observados em dois animais infectados e bem mais frequentes nos outros dois restantes (Figura 2), que também apresentaram fenômenos inflamatórios mais pronunciados. Não foram encontrados ninhos de amastigotas nos plexos nervosos.

Frequentemente foi observada miosite discreta ou moderada focal e/ou difusa, principalmente no TI. Raros ninhos de amastigotas foram encontrados nas fibras musculares (Figuras la e $h$ ).

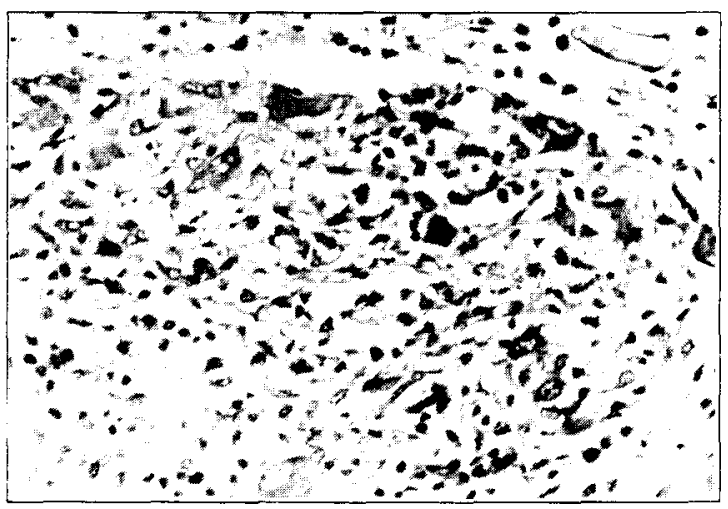

Figura 2 - Terco inferior de esôfago de caio inoculadis com a cepa Be-78 e sacrificado na fase aguda da infecicáo. Ganglionite com infiltrado predominantemente de celulas mononucleadas $e$, fenómenos regressibos dos neurônios Encarquilhamento, tumefaço, picnose, cariolise e tigrólise). HEX $X 360$.

O número total de gânglios e neurônios dos plexos de Auerbach e Meissner de cada animal está contido nas Tabelas 2 e 3 . A média do número de corpos de neurônio/gânglio do plexo de Auerbach nos cães infectados foi de $2,9 \pm 0,71,3,4 \pm 0,95$ e $4,7 \pm 1,49$ nos TS, TM e TI, respectivamente. Nos cães controles, tais médias nas mesmas regiōes foram de 3,3 \pm $0,91,3,2 \pm 1,1$ e $3,8 \pm 1,2$. A análise pelo teste "t" de Student não mostrou variação significativa (TS: $\mathrm{t}=-0,7, \mathrm{p}>0,05 ;$ TM: $\mathrm{t}=0,16$, $\mathrm{p}>0.05 ;$ TI: $\mathrm{t}=0,88, \mathrm{p}>0,05)$, indicando não haver reduçào numérica dos neurônios. Em apenas um único cão foram encontrados gânglios do plexo de Meissner, não sendo possivel fazer a análise estatística.

\section{DISCUSSĀO}

Okumura e col documentaram lesòes do plexo de Auerbach em camundongos inoculados com a cepa $Y$ e afirmaram ter obtido megacólon em alguns destes animais, detectado clinicamente através de estudo radiográfico". Também com relação ao 
Caliari ERO, Caliari MV. Lana M. Tafuri WL. Estudo quantitativo e qualitativo dos plexus de Auerbach e Meissner do esôfago de cáes inoculados com o Trypanosoma cruzi. Revista da Sociedade Brasileira de Medicina Tropical 29:17-20, jan-fel, 1996.

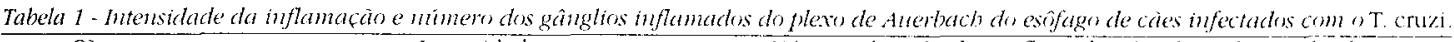

\begin{tabular}{|c|c|c|c|c|}
\hline \multirow[t]{2}{*}{ Cão } & \multirow{2}{*}{$\begin{array}{l}\text { Intensidade } \\
\text { da inflanvaçăo }\end{array}$} & \multicolumn{3}{|c|}{ Número dos gänglios inflamados do plexo de Auerbach } \\
\hline & & Terso superior & Terocoméclio & Teres inferior \\
\hline \multirow[t]{3}{*}{1} & + & 0 & 40 & 80 \\
\hline & ++ & 0 & 0 & 40 \\
\hline & +++ & 0 & 0 & 0 \\
\hline \multirow[t]{3}{*}{2} & + & 1 & 23 & 31 \\
\hline & ++ & () & 0 & 0 \\
\hline & +++ & 0 & 0 & 0 \\
\hline \multirow[t]{3}{*}{3} & + & 22 & 30 & 17 \\
\hline & ++ & 0 & 2 & 0 \\
\hline & +++ & 0 & 0 & 0 \\
\hline \multirow[t]{3}{*}{4} & + & 61 & 53 & 311 \\
\hline & ++ & 2 & 7 & 36 \\
\hline & +++ & 0 & 0 & 4 \\
\hline
\end{tabular}

+ discreto; ++ moderado; +++ intenso.

Tabela 2 - Resultadus da avaliacain quantitativa dos plexos de Anerbach e Meisiner do esofago de cries controles

\begin{tabular}{|c|c|c|c|c|c|c|c|}
\hline \multirow[t]{3}{*}{ Cão } & & \multicolumn{2}{|c|}{ Teroo superior } & \multicolumn{2}{|c|}{ Terco médio } & \multicolumn{2}{|c|}{ Terco inferions } \\
\hline & & Plexo de & Plexo de & Plexo de & Plexode & Plexodk & Plexode \\
\hline & & Auerbach & Meissner & Auerbach & Meissner & Aucrbach & Meissner \\
\hline \multirow[t]{2}{*}{1} & Neurónios & 475 & 0 & 421 & 0 & 1002 & () \\
\hline & Gânglios & 132 & 0 & 98 & 0 & 297 & () \\
\hline \multirow[t]{2}{*}{2} & Neurônios & 687 & 0 & 370 & () & 4930 & () \\
\hline & Gânglios & 213 & 0 & 231 & 0 & 920 & () \\
\hline \multirow[t]{2}{*}{3} & Neurônios & 627 & 11 & 377 & 0 & $2(10) 2$ & 25 \\
\hline & Gânglios & 144 & 7 & 111 & 0 & 495 & 7 \\
\hline \multirow[t]{2}{*}{4} & Neuronios & 420 & 0 & 540 & 0 & 1110 & () \\
\hline & Gânglios & 195 & 0 & 150 & 0 & 465 & 0 \\
\hline
\end{tabular}

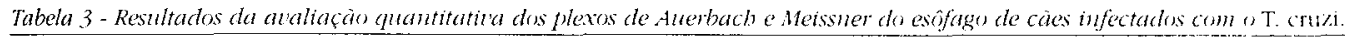

\begin{tabular}{|c|c|c|c|c|c|c|c|}
\hline \multirow[t]{3}{*}{ Cào } & & \multicolumn{2}{|c|}{ Tercosuperior } & \multicolumn{2}{|c|}{ Terço médio } & \multicolumn{2}{|c|}{ Terous inferior } \\
\hline & & Plexo de & Plexo de & Plexo de & flexode & Plexo de & Plexo de \\
\hline & & Auerbach & Meissner & Auerbach & Meissner & Aucrbach & Meissner \\
\hline \multirow[t]{2}{*}{1} & Neurônios & 280 & 0 & 250 & 0 & 1560 & 0 \\
\hline & Gânglios & 130 & 0 & 130 & 0 & 430 & () \\
\hline \multirow[t]{2}{*}{2} & Neurônios & 197 & 0 & 226 & () & 2491 & (1) \\
\hline & Gânglios & 74 & 0 & 71 & 0 & 627 & 0 \\
\hline \multirow[t]{2}{*}{3} & Neurônios & 323 & () & 701 & 0 & 1843 & 0 \\
\hline & Gânglioss & 107 & 0 & 199 & 0 & 420 & 0 \\
\hline \multirow[t]{2}{*}{4} & Neurónios & 623 & 0 & 546 & 0 & 3556 & () \\
\hline & Gînglios & 158 & () & 130) & 0 & 515 & () \\
\hline
\end{tabular}

esôfago, parece não haver relato seguro na literatura no que se refere à indução de mega. Foi relatado megaesôfago em cães inoculados com a cepa Y, porém os resultados e a documentação fotográfica se restringem somente à macroscopia, deixando dúvidas sobre a causa real da dilatação que também não foi analisada quantitativa e estatisticamente $^{10}$. Marsden e col também afirmam terem obtido megaesôfago em um macaco inoculado com a cepa Peru, mas no trabalho não há qualquer documentação fotográfica à respeito da lesão. Lesões e infiltrado inflamatório no plexo mioentérico do esôfago foram demonstrados na fase crônica da infecção em coelhos inoculados com a cepa Ernestina e com antígenos de $T$. cruzi $i^{12}$. Guimarães e Miranda afirmam ter encontrado megaesôfago em macaco rhesus após 10 anos de infecção. Todavia, quer nos parecer que thes faltaram muitos parâmetros para chegarem a esta conclusão. A tuberculose parece ter sido a maior causa das lesōes do esôfago e a presença do parasito neste órgão poderia ser secundária a mecanismos de imunossupressão".

Até o momento tem-se demonstrado que as cepas Be-62 e Be-78 são mais miotrópicas 
Caliani ERO, Caliani MV, Lana M. Tafint WL. Estudo quantitativo e qualitativo dos plexos de Auerbach e Meissner do esoffago de cäes inoculados com o Trypanosoma cruzi. Retista da Sociedade Brasileira de Medicina Tropical 29: 17-20, jan-fer; 1996.

do que neurotrópicas e, em relação ao tecido muscular, elas parasitam e lesam mais intensamente as miocélulas estriadas cardiacas ${ }^{515}$. Talvez por esta razào, sendo mais discreta a miosite do esofago dos càes estudados neste experimento, os plexos nervosos intramurais indiretamente sejam menos atingidos. Este fato não acontece como no coração, pois como já demonstrado anteriormente, o sistema nervoso autonomo intracardíaco é bem mais atingido principalmente via periganglionite $e$ ganglionite secundárias à epicardite focal e/ou difusa do átrión.

Temos 17 càes no biotério inoculados com as cepas Be-62, Be-78 e Colombiana que sobreviveram a fase aguda e estão com mais de 8 anos de infeccao comprovada pelo xenodiagnóstico e ELISA. Até o momento não se verificou megaesôfago e nem megacólon em 11 càes já sacrificados na fase crônica.

A cepa $\mathrm{Be}-78$ inoculada em càes nào foi capaz de produzir lesoes significativas nos plexos nervosos intramurais do esôfago à ponto de induzir a formação de um megà. Porém, os fenômenos inflamatórios e as lesôes observadas neste experimento talvez possam ser semelhantes às lesoes básicas iniciais de esoffagos humanos na fase aguda da infeç̧àon.

\section{SUMMARY}

A quantitatite and qualitative study uas conducted on the Auerbach and Meissner plexuses of the esophagus of four chagasic dogs sacrificed during the acute phase of infection. Ganglionitis and periganglionitis of the Alserbach plexus ranged from mild to moderate and induced significant neuronal lesions, especially in two animals. The ganglionis of the Meissner plexus were obsened in small mumber which did not permit any analysis. Mild or moderate myositis uas obsened mainly in the lower third of the esophagus and was rarely associated with amastigote nests. Ganglion and neurom connts did not demonstrate denemation. Although the formation of megaesophagus was not induced in ainy dog. lesions of the Auerbach plexus and mycells of the esophagus were observed during the acute phase of chagasic infection. To our knowledge. this is the first systematic quantitative and qualitatine study of the Auerbach and Meissner plexuses of the esophagus in experimental trypanosomiasis conzi.

Key-uords: Fisophagus. Auerbach and Meissner plexuses. Trypanosoma cruzi. Acute phase. Dog.

\section{AGRADECIMENTOS}

A Maria Chaves pelo auxílio técnico prestado.

\section{REFERÊNCIAS BIBLIOGRÁFICAS}

1. Andrade ZA.The canine model of Chagas' discase. Memórias do Instituto Oswaldo Cruz 79:77-83, 1984.

2. Brener $Z$. Therapeutic activity and criterion of cure in mice experimentaly infected with Trypanosoma cruzi. Revista do Instituto de Medicina Tropical de São Paulo 4:389-396, 1962.

3. Caliari MV, Lana $M$, Leite VHR, Tafuri WL. Morphological and morphometric study of atrial specific granules and other secretory components in experimentally infected dogs with Trpanosoma cmizi. International Journal of Experimental Pathology 76:299-307, 1995.

4. Caliari MV, Lana M, Oliveira ER, Barbosa AJA, Tafuri WL. Immunocytochemical study of tissue parasitism of dog adrenal glands in experimental Chagas' disease. Parasite 1:397-400, 1994.

5. Caliari MV, Lana M, Caliari ERO, Tafuri WL. Cardiac plexus of dogs experimentally infected with Trypanosoma cruzi: inflammatory lesions and quantitative studies. Revista da Sociedade Brasileira de Medicina Tropical 28:7-11, 1995.

6. Guimarães JP, Miranda A. Megaesôfago em macaco Rhesus com 10 anos de infecção chagásica. In: Congresso Internacional sobre Doença de Chagas 2:657-671, 1959.

7. Lana M, Chiari E, Tafuri WL. Experimental Chagas' disease in dogs. Memórias do Instituto Oswaldo Cruz 87:59-71, 1992.

8. Marsden PD, Seah SKK, Draper CC, Pettitt LE, Miles MA, Voller A. Experimental Trypanosoma cruzi infections in rhesus monkeys. II. The early chronic phase. Transactions of the Royal Society of Tropical Medicine and Hygiene 70:247-251, 1976.

9. Okumura M. Contribuição para o estudo das lesões dos neurônios do plexo mioentérico do colo na moléstia de Chagas experimental no camundongo branco (Mus musculus). Revista do Hospital das Clínicas da Faculdade de Medicina de São Paulo 22:192-203, 1967.

10. Okumura M, Neto AC. Produção experimental de "megas" em animais inoculados com Trypanosoma cruzi. Revista do Hospital das Clínicas da Faculdade de Medicina de São Paulo 16:338-341, 1961 .

11. Tafuri WL, Lopes E, Numan B. Doença de Chagas congênita. Estudo clínico-patológico de um caso com sobrevida de seis meses. Revista do Instituto de Medicina Tropical de São Paulo 15:322-330, 1973.

12. Teixeira ARL, Teixeira ML, Santos-Buch CA. The immunology of experimental Chagas' disease. IV. Production of lesions in rabbits similar to those of Chronic Chagas' disease in man. American Journal of Pathology 80:163-180, 1975. 